\title{
As múltiplas faces do "Doutor Lao" vistas pelo cinema e pela literatura
}

\section{The multiple faces of "Doctor Lao" represented in the movies and in literature}

Fábio Augusto Steyer ${ }^{*}$

\begin{abstract}
Resumo: As relações e intersecções entre cinema e literatura são analisadas muitas vezes a partir de uma visão preconceituosa que desrespeita as especificidades de cada área. Ambas possuem linguagem própria e características bastante singulares enquanto meios de expressão. Nesse sentido, o objetivo deste trabalho é analisar comparativamente um dos clássicos da literatura fantástica mundial - "As Sete Faces do Doutor Lao" (1935), de Charles Finney, e sua versão cinematográfica, dirigida por George Pal e lançada em 1964, a partir dos conceitos de "imagem-tempo" e "imagem-movimento", de Gilles Deleuze. A ideia é fugir dos preconceitos e analisar quais as soluções cinematográficas encontradas na adaptação da obra literária para o cinema. Ou seja: de que maneira a equipe do filme procurou adaptar uma linguagem textual para uma linguagem imagética e sonora, observando as especificidades estéticas de cada área.

Palavras-chave: Literatura. Cinema. Linguagem.

Abstract: The relationships and intersections between cinema and literature are often analyzed from a biased view that disregards the particularities of each area. Both have their own unique language and characteristics as a means of expression. In this sense, the objective of this study is to analyze one of the great classics of world literature - "The Seven Faces of Doctor Lao" (1935), Charles Finney, and its film version, directed by George Pal in 1964, from concepts of "image-time" and "image-movement" of Gilles Deleuze. The idea is to avoid the prejudices and consider what solutions were encountered in adapting the literary work to film, in other words how the film team tried to adapt a textual language to an imagery and sound language taking into consideration the specific aesthetics of each area.

Keywords: Literature. Film. Language.
\end{abstract}

Adaptar uma obra literária para o cinema certamente não é tarefa fácil. Mais difícil ainda é analisar as perdas e ganhos de uma adaptação desse tipo, além dos objetivos de quem se propõe a esta empreitada (que nem sempre incluem uma proposta de "fidelidade" ao livro), tendo em vista que se trata

Professor Adjunto da Universidade Estadual de Ponta Grossa (UEPG). Doutor em Literatura pela Universidade Federal do Rio Grande do Sul (UFRGS). E-mail: fsteyer@uol.com.br. 
de linguagens completamente diferentes. Deste modo, parece-me totalmente ultrapassada aquela ideia que infelizmente ainda existe, principalmente nos estudos literários, de que um é melhor do que o outro, geralmente o livro em relação ao filme, e etc. e tal.

Portanto, as dificuldades deste tipo de abordagem não serão diferentes com relação à análise comparativa de "As Sete Faces do Doutor Lao", um clássico da literatura fantástica publicado originalmente em 1935, da autoria de Charles G. Finney, e sua adaptação cinematográfica, dirigida por George Pal e lançada em 1964.

O objetivo maior deste artigo, pensando a temática a partir dos pressupostos de Gilles Deleuze sobre a narrativa cinematográfica, é mostrar de que maneira um enredo mais sofisticado (o do livro) acabou se tornando mais tradicional (no filme). Como ambos podem ser considerados como "narrativas", cada um com sua linguagem própria, o que desejamos demonstrar, sem valorar as obras como "melhor" ou "pior", são as diferenças de suas construções narrativas: uma baseada naquilo que Deleuze denomina "imagens-movimento" (que compõem a narrativa clássica e linear); e a outra, no que ele chama de "imagens-tempo" (que constituem a narrativa moderna, plural e não-linear). Embora as considerações de Deleuze sejam específicas sobre o cinema, podem perfeitamente servir como referência à literatura, visto que, como dito anteriormente, ambas as produções são "narrativas".

A inspiração para a novela, que chegou a receber o prêmio da Associação Nacional de Livreiros dos Estados Unidos para "melhor livro de ficção do ano", veio do período em que o autor esteve na China, no final da década de 1920. De volta aos EUA, Finney ocupou cargos em importantes jornais norte-americanos e continuou publicando textos relacionados à literatura fantástica. O lançamento do filme deu nova vida ao livro, quando foram publicadas inúmeras novas edições em vários países.

O húngaro George Pal, formado originalmente em arquitetura, é diretor de referência para a história do cinema fantástico. Além de "As Sete Faces do Doutor Lao", esteve profundamente ligado à obra de H. G. Wells, um dos maiores nomes da literatura de ficção científica. Foi produtor do filme "A

\footnotetext{
${ }^{1}$ Lembre-se aqui das discussões contemporâneas sobre a ampliação do conceito de literatura e de narrativa, tendo em vista a enorme quantidade de formas ficcionais híbridas do mundo atual. Uma ótima análise a respeito pode ser encontrada no seguinte texto: ZAPPONE, Mirian H. Y. Fanfics - um caso de letramento literário na cibercultura? In: Letras de Hoje, Porto Alegre, PUCRS, v. 43, n. 2, p. 29-33. 
As múltiplas faces do "D outor Lao" vistas pelo cinema e pela literatura.

Guerra dos Mundos" (1953), diretor de "A Máquina do Tempo" (1960), ambos baseados em Wells, e coautor da sequência do livro - "The time machine 2" - juntamente com Joe Morhaim.

"As Sete Faces do Doutor Lao", vencedor de um Oscar especial para Melhor Maquiagem (categoria que não existia na época) e indicado para o de Efeitos Especiais, tem roteiro de Charles Beaumont e é estrelado por Tony Randall no papel-título (as "sete faces" que renderam ao filme o prêmio de melhor maquiagem), Barbara Eden (de "Jeannie é um Gênio") como a mocinha e Arthur O'Connel (de "Viagem Fantástica") como o vilão Clint Stark. Interessante comentar que o papel-título originalmente teria sido oferecido a Peter Sellers, o protagonista de "A Pantera Cor-de-Rosa".

As semelhanças entre livro e filme são muitas. Mas as diferenças também são enormes. Podemos começar dizendo que no livro não há muita preocupação em contar uma história em sentido mais tradicional e linear (com início, meio e fim), com um sentido moralizador ou moralizante evidente, naquilo que, em termos de narrativa, Gilles Deleuze chamou de "cinema clássico", baseado num regime de "imagens-movimento" - para já fazermos uma primeira relação entre a teoria da narrativa literária e a do cinema, que, no fundo, são a mesma, apesar das linguagens que as viabilizam serem diferentes. O livro de Finney é calcado na própria experiência do fantástico, das criaturas fantásticas que nele aparecem e na sensação de que tudo é uma experiência ligada ao mundo da fantasia e suas conexões com a realidade da cidadezinha de Abalone, onde a história se passa.

Já o filme é muito mais convencional. Temos um vilão (Clint Stark) que simplesmente deseja comprar toda a cidade, enganando a população, porque é o único a saber que em breve por lá deve passar uma estrada de ferro que vai valorizar as terras. Nesse sentido, a vinda do circo do Doutor Lao à cidade, aliada ao "mocinho" do filme, o editor-chefe do jornal local, parece ser o elemento de salvação da população contra o inescrupuloso fazendeiro. Este maniqueísmo entre o bem e o mal, o vilão e o mocinho, não aparece no livro de Finney, em que o elemento mais importante é o componente fantástico das criaturas apresentadas pelo Doutor Lao a partir da imaginação do autor.

Também são diferentes algumas estratégias narrativas utilizadas em ambas as obras. As do livro são mais sofisticadas, digamos assim, o que não

\footnotetext{
Para saber mais sobre os conceitos de "imagem-tempo" e "imagem-movimento", de Gilles Deleuze, consultar: PELBART, Peter Pál. O tempo não-reconciliado: imagens de tempo em Deleuze. São Paulo: Contexto, 1999.
} 
significa que sejam melhores ou piores, mais ou menos eficientes. Como foi dito anteriormente, são linguagens diferentes, e nem tudo o que aparece num texto literário pode ser "fielmente" representado num filme (e vice-versa). Mas as estratégias do livro são, sim, mais sofisticadas, embora a história essencial seja a mesma: na pequena cidade de Abalone, nos confins do estado do Arizona, nos Estados Unidos, chega um circo diferente, repleto de criaturas fantásticas e bizarras, cujo dono é o estranho Doutor Lao, um chinês de origem duvidosa. Tanto o livro quanto o filme se prendem, então, na forma com que a população se relaciona com o circo e suas criaturas.

Um dos elementos narrativos mais interessantes do livro é que, antes da primeira sessão do circo, as personagens e suas famílias vão sendo apresentadas uma após a outra, como se fossem capítulos diferentes, e a partir daí se segue sua visita ao circo, sempre conhecendo uma de suas atrações. No filme, isso não acontece, pois todas as personagens aparecem ao mesmo tempo chegando ao circo. No livro, portanto, a personagem é apresentada e vai a uma atração do circo. Depois outra personagem, e assim por diante...

Outra estratégia marcante do livro são as longas explicações que o Doutor Lao oferece aos espectadores sobre a origem, as características e a história das diferentes criaturas fantásticas apresentadas no circo. São assim, por exemplo, as descrições do sátiro (páginas 34-36), da medusa (páginas 4346) e do cão das sebes (páginas 50-52). Essas descrições são extremamente detalhadas e incluem a forma como o Doutor Lao capturou as diferentes criaturas. De certa maneira, dão unidade à narrativa, ligando as diferentes partes do texto, cada uma relacionada a uma determinada criatura fantástica. A seguir, reproduzimos, como exemplo, uma pequena parte da descrição sobre a medusa:

O doutor Lao fez uma pausa, logo prosseguiu: - Essa medusa que temos diante de nós é jovem. Eu calcularia sua idade em menos de 100 anos. Conhecedores da beleza feminina me têm dito que ela é invulgarmente formosa, que possui encanto muito superior ao da mulher humana média. E eu admito que há, na flexibilidade de seus braços, na projeção de seus seios, nos contornos de seu rosto, muito daquilo que sem dúvida atrai o que existe de artístico no homem. Contudo, ela é uma medusa temperamental. Às vezes tento conversar com ela, descobrir o que ela pensa a respeito de ficar sentada aqui a contemplar o mundo refletido num espelho, quando é capaz de despovoar toda uma cidade simplesmente caminhando pelas ruas e fitando os passantes. Mas ela não me responde. Apenas me fita pelo espelho com fastio - ou será pena e divertimento? - e acaricia suas cobras, sonhando, sem dúvida, com o último homem a quem roubou a vida. (FINNEY, 1979, p. 45). 
As múltiplas faces do "Doutor Lao" vistas pelo cinema e pela literatura.

Essas descrições até aparecem no filme, mas de uma forma muito mais discreta, sem se constituírem, como no livro, elementos de coesão e coerência da narrativa.

Elas também podem ser associadas à ideia de imagem-tempo, de Deleuze, pois temos a impressão de que o tempo da narrativa fica parado, que a perspectiva é da representação da duração do "tempo real" da ação, o que foge da narrativa clássica e nos remete à narrativa moderna. Afinal, segundo Deleuze, na narrativa clássica, baseada num regime de imagens-movimento:

uma imagem sempre produz uma percepção, de modo que a sequência sensório-motora de nossas expectativas, corroboradas pelas narrativas clássicas, é passar logo a uma ação e, por conseguinte, a uma relação causal. [...] O segredo [da narrativa moderna, baseada nas imagens-tempo] consistiria em retardar esse efeito, produzindo hiatos, gerando afecções ${ }^{3}$.

Deste modo, de acordo com Peter Pál Pelbart, tradutor de Deleuze no Brasil, temos, no livro, "mais perambulação do que ação". (PELBART, 1999, p. 107).

O mesmo acontece com outro procedimento marcante no livro e que não existe no filme, relacionado à chegada do circo na cidade. $O$ texto se desenvolve acentuadamente em torno dos diálogos de várias pessoas que não viram o circo chegar, e que questionam por onde ele teria vindo. É o caso do agente da estação da estrada de ferro e do inspetor sanitário que fazia plantão na estrada, personagens que sequer aparecem no filme.

Também é importante no texto a extensa parte (várias páginas) em que as personagens assistem ao desfile do circo nas ruas da cidade e discutem sobre as criaturas e sua procedência. Ninguém tem certeza sobre o que são aquelas estranhas criaturas e animais, também confundidas com humanos esquisitos. O desfile não aparece no filme e, portanto, não representa momento de grande força dramática e narrativa como no livro, em que também podemos associar os comentários ao conceito de imagem-tempo.

Um exemplo é a descrição relacionada ao militar Larry Kamper, que reproduzimos a seguir:

\footnotetext{
${ }^{3}$ GARROCHO, Luiz Carlos. Anotações sobre a imagem-corpo nos curtas de Ricardo Júnior. Publicado em: <http://www.polemica.uerj.br/pol24/cimagem/p24_garrocho.htm>. Acesso em: 03 set. 2010. 
Fabio Augusto Steyer

Seguindo pela rua principal, a seis quarteirões dali, Larry encontrou o desfile. Percebendo que ainda era cedo demais para o espetáculo, forçou caminho entre a multidão de mexicanos acotovelados junto ao meio-fio, para dar uma olhadela na parada.

Quase riu ao vê-la. Apenas três carrocinhas escangalhadas puxadas por animais, a primeira conduzida por um velho chinês, a segunda por um homem pálido e barbudo, a última por um camarada com cara de judeu e um capuz de chifres de bode. Na carroça do chinês havia uma enorme cobra cinzenta enrolada, na segunda um urso e na última um cachorro verde.

- Ei! - falou o homem que estava ao lado de Larry. - Que espécie de animal é aquele que está puxando a primeira carroça?

Larry olhou e viu um cavalo com um fino chifre branco no meio da testa.

- É alguma invencionice - respondeu Larry. - Como se chamam esses bichos? Monocornos? Não, não é não... Unicórnios? Isso! Unicórnios. Acho que o sujeito pegou um cavalo e fez um unicórnio, pregando um chifre na cabeça dele.

- Pode ser, mas esse cavalo aí é diferente de todos que eu já vi - disse o homem. - Olha só aquele rabo. Já viu um cavalo com um rabo daquele?

- Bem, não entendo muito de cavalos - disse Larry. - Passei seis anos na infantaria. Mas unicórnio não é não. Isso eu sei, porque unicórnios não existem, nem nunca existiram.

- Bem, mas cavalo aquilo não é - falou o homem. Fui criado junto de cavalos e sei muito bem como é um cavalo. E aquele bicho pode ser tudo, menos um cavalo.

- Então deve ser um aleijão - disse Larry.

$[\ldots]$

- Não sei não - disse Larry. Mas tem qualquer coisa esquisita nisso tudo. Um desfile de circo só com três carroças! Nossa! Ei, que animal é aquele na última carroça? 
As múltiplas faces do "Doutor Lao" vistas pelo cinema e pela literatura.

- Agora você me pegou, amigo. Parece um cachorro.

- Aquilo não é cachorro nem aqui nem na China - disse Larry.

$[\ldots]$

- Sabe de uma coisa, quero mais que esse circo vá para o inferno - disse Larry. Estou com dinheiro. Vamos tomar uma cerveja em algum lugar. (FINNEY, 1979, p. 15-16).

E a partir daí segue a discussão de diversas pessoas da cidade sobre o desfile e suas misteriosas criaturas, o que, como já foi dito, é algo marcante no livro, e que não aparece no filme.

Mas talvez o que de mais diferente exista entre as duas obras e que talvez represente mesmo uma das partes mais originais do livro, e praticamente impossível de ser reproduzida no filme enquanto estratégia narrativa, é o que Finney denomina "O Catálogo", uma espécie de apêndice ou glossário no final do texto que, de acordo com o autor, representa uma "explicação do óbvio, que tem de ser lido para ser apreciado".

São dezenove páginas em que são apresentados, muitas vezes com alta dose de humor e ironia, as diferentes personagens e objetos que aparecem no decorrer do enredo. Há inclusive explicações que não são dadas durante a narrativa e que neste apêndice ajudam o leitor a entender melhor algumas situações e personagens. São apresentados no Catálogo: 1) Personagens masculinos; 2) Personagens femininos; 3) Personagens infantis; 4) Os animais; 5) Os deuses e deusas; 6) As cidades; 7) As estatuetas, ícones, artefatos e ídolos; 8) As perguntas, contradições e obscuridades; 9) As comidas.

A seguir, algumas destas definições. Importante prestar atenção no humor com que o autor se refere a algumas personagens:

1. Personagens masculinos

Doutor Lao: um chinês.

O morto que Apolônio ressuscitou: Arnold R. Todhunter. Vivia num lote de terra cedido pelo governo. Mais tarde um repórter da Tribuna o entrevistou. Indagado a respeito das horas que passou nos braços da 
Fabio Augusto Steyer

morte, afirmou que estava prestes a receber uma harpa e um camisolão quando Apolônio o trouxe daquela para pior. Disse que em sua opinião o céu era parecido com um anúncio do Sul da Califórnia que ele vira certa vez.

Homens morenos na vida da Sra. Cassan: italianos, espanhóis e franceses.

\section{Personagens femininos}

Agnes Birdsong: diziam os rapazes que depois que ela aprendeu a fumar e beber tornou-se ótima companhia. O circo do doutor Lao alargou sua visão, deu-lhe em que pensar quando, insone, revirava-se em seu leito de noite; ou quando, enfastiada, ouvia os alunos recitar a lição de sintaxe, de dia.

\section{Personagens infantis}

O garotinho mulato gorducho: durante sete anos, comeu. Depois, durante alguns minutos, foi comido. Terminou sendo incorporado à estrutura celular da serpente, honraria que não apreciou.

\section{Os animais}

Medusa: tão frígida ela própria como as figuras de pedra em que transformava os homens. (FINNEY, 1979, p. 97-116).

Na parte 7, a das Estatuetas, ícones, artefatos e ídolos, o autor simplesmente se refere ao material de que foram feitos. Exemplo: "Esfinge: terracota. Yottle: bronze. Kate: calcedônia cornalina (esta última uma divertida referência à mulher transformada em pedra pela medusa)".

E a parte mais interessante deste Catálogo é aquela em que Finney, ele próprio, como autor, apresenta questionamentos referentes à narrativa, todos extremamente irônicos, como que num papel de autocrítico, de ombudsman ou algo parecido. Vários pontos obscuros e não explicados do enredo são aí referidos, como, por exemplo, os que colocamos a seguir:

1. Se a serpente marinha era tão venenosa como afirmava, por que não matou a quimera quando a mordeu? 
As múltiplas faces do "D outor Lao" vistas pelo cinema e pela literatura.

6. Por que o doutor Lao não notou algo estranho ao encontrar Agnes Birdsong e o sátiro em colóquio tão comprometedor?

8. O que Mumbo Jumbo fez com a nórdica de cabelos louros?

9. Se o circo não chegou a Abalone pela estrada de ferro nem por caminhão, como foi, afinal, que chegou lá?

11. Se Apolônio era tão grande mágico, por que perdia seu tempo andando ao léu com um circo mambembe?

12. Uma vez que a tradição nos diz que as quimeras eram invariavelmente fêmeas, como sucede que a do doutor Lao fosse macho?

13. Seria por essa mesma razão que Tu-jeng, quando o doutor Lao ali capturou o sátiro, era uma aldeia perto da Grande Muralha, quando hoje é um subúrbio de Tientsin? (FINNEY, 1979, p. 97-116).

Há várias atrações que aparecem no livro e não no filme. Exemplos: quimera, lobisomem, sereia, a dança dos sacerdotes negros, o sabá das feiticeiras. E mesmo nas atrações que estão presentes em ambos, o tom erótico é muito mais evidente no livro. Logo de início, já no anúncio do circo colocado no jornal da cidade, divulga-se um "espetáculo erótico só para homens", e aparece a palavra "pornográfico". No encontro da professora Agnes Birdsong com o sátiro (que no filme é o deus Pã), embora a solução cinematográfica de rodar a câmera e as duas personagens de maneira ininterrupta seja extremamente eficiente em "captar" o clima erótico da cena descrita no livro, em que uma "moça calma e inteligente" (como Finney a descreve) fica atordoada por sentimentos, digamos, indecentes, no texto a intensidade é muito mais forte: o sátiro a belisca, arranha suas coxas e lhe morde os ombros. Além disso, há a tal dança dos sacerdotes negros, com um deus chamado Mumbo Jumbo, um fauno, ninfas e uma loura nórdica! Nada desse espetáculo é referido no filme.

No filme, temos o adivinho Apolônio, que é cego, e o mágico Merlin, que são duas personagens diferentes. No livro, trata-se apenas de uma personagem: Apolônio. Como mágico, ele faz praticamente tudo o que aparece no filme. Mas também ressuscita um cadáver, o que não está na adaptação cinematográfica. No filme, Merlin faz a mulher que virou pedra (ao olhar para a medusa) voltar ao normal. No livro, recheado de ironias (marca de estilo que 
Fabio Augusto Steyer

não aparece no filme), ela não só permanece como pedra como acaba sendo alvo do comentário de um geólogo: "Calcedônia maciça. Nunca vi uma variedade de coloração tão bonita em minha vida, sinceramente. Calcedônia cornalina. É uma das melhores pedras de construção que existe". (FINNEY, 1979, p. 47).

O diálogo entre Apolônio e a Sra. Howard Cassan, embora seja muito parecido nas duas obras, tem algumas diferenças importantes. No filme, o adivinho diz que ela nunca mais terá homens em sua vida, que nunca irá encontrar petróleo em suas terras e que viverá uma vida repleta de mesmice até morrer esquecida por todos. A viúva sai arrasada da consulta, mesmo que em seguida diga aos outros que as previsões de Apolônio foram as melhores possíveis. No livro (e novamente temos a marca da ironia e do deboche) a conversa continua, e a Sra. Cassan chega a dar uma cantada em Apolônio:

- Pobre homem, pobre homem! O senhor não é muito mais velho do que eu, não é? Eu também fui magoada. Por que não poderíamos ser amigos, ou mais que amigos, quem sabe, e juntos remendar os farrapos de nossas vidas? Acho que eu seria capaz de compreendê-lo, consolá-lo e tomá-lo sob meus cuidados.

- Minha senhora, eu tenho quase 2 mil anos de idade, e sempre fui solteiro. É tarde demais para começar.

- Ah, como o senhor é engraçado! Eu adoro brincadeiras! Nós nos daríamos esplendidamente, os dois. Tenho certeza!

- Sinto muito. Eu lhe disse que não haveria mais homens em sua vida. Não tente fazer com que eu me desdiga, por favor. A consulta terminou. Boa tarde.

A Sra. Cassan começou a dizer alguma coisa, mas não havia mais ninguém com quem falar. Apolônio havia desaparecido com aquela presteza dominada apenas pelos mágicos de maior experiência. A Sra. Cassan saiu para o clarão da tarde ensolarada. (FINNEY, 1979, p. 63-64).

Outro trecho de diferenças marcantes entre as duas obras é o episódio da serpente que fala. No filme, para demarcar bem aquela ideia de enredo em estilo narrativo clássico (segundo Deleuze) e as posições de vilão e mocinho da história, quem fala com a cobra é o senhor Stark, o fazendeiro malvado 
As múltiplas faces do "D outor Lao" vistas pelo cinema e pela literatura.

que deseja comprar todas as terras da cidade. Aliás, na parte final do livro, quando ocorre o espetáculo que mostra a destruição da cidade de Woldercan, não aparece nenhuma relação com a cidade de Abalone e seus habitantes, $o$ que acontece claramente no filme, justamente demarcando o enredo tradicional e o embate entre o bem e o mal. Mas vamos voltar à história da cobra. Se no filme é o vilão Stark que fala com a cobra, que acaba mostrando toda a sua insignificância enquanto ser humano, no livro a conversa se dá com o Sr. Etaoin, o editor-chefe do jornal da cidade, que no filme é o mocinho da história.

Durante a conversa, que é bem mais amistosa do que no filme, eles falam sobre comida (a da cobra foi um garotinho mulato!), amor e a comparação entre os homens e as cobras é inevitável. Para tanto, um dos procedimentos narrativos utilizados é o seguinte: após cada comentário feito pela cobra, ela pergunta ao seu interlocutor como os homens se comportam na mesma situação. Vejamos um trecho:

Etaoin: E encontraste tua companheira?

A cobra: Encontrei-a. Junto de uma ilha de pedras escuras. Era reservada e recatada. Deslizou para cima das rochas e silvou para mim. Deslizei em sua direção. Minha paixão a incendiou; meu amor moderou seu recato. Diz-me: os homens mordem as mulheres no pescoço quando as cortejam?

Etoin: às vezes.

A cobra: Nós também. Mordi-a no pescoço e ela se pendurou em minha mandíbula. Eu sentia seu veneno circular em mim. Mas não me fez mal; nem o meu lhe foi nocivo. Depois puxei-a daquela ilha rochosa, dei uma ou duas voltas ao redor dela e assim lutamos nas ondas nervosas e agitadas. Lembro-me do céu encoberto e do trovão que roncava, como se os elementos estivessem perturbados com os nossos folguedos. Diz-me: os homens cansam-se das mulheres depois que se deitam com elas?

Etaoin: às vezes.

A cobra: Nós também. (FINNEY, 1979, p. 73-74).

E por aí segue o diálogo, no mesmo estilo narrativo de comparação entre homens e cobras. 
Bom... Vimos até agora uma série de diferenças e semelhanças entre o livro de Finney e sua adaptação cinematográfica. Vários outros trechos poderiam ser analisados, mas vamos ficar por aqui para não estender demais este texto. O mais importante, como já foi dito, é perceber que enquanto o filme tem soluções mais simples, dentro de um enredo mais tradicional, demarcando bem os vilões e heróis, almejando a ideia de final feliz (até o vilão fica bonzinho, devido à influência do Doutor Lao), o livro é mais sofisticado nas suas estratégias narrativas, na intensa exploração do fantástico e do deboche e por não necessariamente buscar uma solução definitiva para a história, que não tem um final propriamente dito. O circo do Dr. Lao vem, vai embora e não há nada de solução final nisso. Poderíamos falar do sacrifício da virgem no espetáculo final sobre Woldercan, em homenagem ao deus Yottle, em que as doze concorrentes foram descritas por Finney como "doze bocados de sexo maturo mas ainda não provado" (p. 93). Ou então da transformação do lobisomem em uma mulher de 300 anos! E tantas outras bizarrices desta que é uma das clássicas histórias da literatura fantástica.

Mas preferimos ficar com a definição do próprio Doutor Lao. Quando a professora Agnes Birdsong o questionou sobre por que o símbolo do mal surgia em todas as cenas e atrações do circo, o velho chinês respondeu:

- O mundo é a minha ideia.- disse ele. O mundo é a minha ideia. É esse o mundo que eu lhes apresento. Tenho meu próprio sistema de pesos e medidas e meu próprio quadro de valores. A senhora tem o direito de ter o seu. (FINNEY, 1979, p. 89).

Talvez esta seja mesmo a diferença principal entre o livro e o filme. Duas linguagens diferentes. Duas propostas diferentes de narrativa. Duas "escalas de valores, de pesos e medidas". Uma, mais simples, para o grande público, baseada nas imagens-movimento e na narrativa clássica que sustenta a indústria cinematográfica desde os primórdios da Sétima Arte; outra, mais sofisticada, voltada a um leitor mais exigente e aberto à pluralidade da narrativa moderna, baseada nas imagens-tempo. Mas ambas muito bem sucedidas.

Este é o mundo do Doutor Lao.

E no final de tudo, "a lona dobrou-se, fechando-se. Estava terminada a função do circo do doutor Lao. E em meio à poeira e à canícula os habitantes de Abalone foram para casa ou para onde quer que estivessem indo." (p. 95) 
As múltiplas faces do "D outor Lao" vistas pelo cinema e pela literatura.

\section{Referências}

AS SETE faces do Dr. Lao. (Seven faces of Dr. Lao). Direção: George Pal. EUA. Produção: Metro-Goldwyn-Mayer. Distribuição: Metro-Goldwyn-Mayer - Turner Entertainment. 1964. (101 min).

DELEUZE, Gilles. Cinema: a imagem-movimento. Tradução de Stella Senra. São Paulo: Brasiliense, 1985.

FINNEY, Charles. As sete faces do Dr. Lao. Rio de Janeiro: Francisco Alves, 1979.

GARROCHO, Luiz Carlos. Anotações sobre a imagem-corpo nos curtas de Ricardo Júnior.

Disponível em: <http://www.polemica.uerj.br/pol24/cimagem/p24_garrocho.htm>. Consultado em: 03 set. 2010.

PELBART, Peter Pál. O tempo não-reconciliado: imagens de tempo em Deleuze. São Paulo: Contexto, 1999.

ZAPPONE, Mirian H. Y. Fanfics: um caso de letramento literário na cibercultura? In: Letras de Hoje, Porto Alegre, PUCRS, v. 43, n. 2, p. 29-33.

Recebido para publicação em 21 jun. 2010 Aceito para publicação em 03 set. 2010 